\title{
High Voltage Overhead Powerlines Routing in Central Nigeria using GIS-MCDA Approach and Environmental Impact Factors
}

\author{
Osarenren O., Ehiorobo J. O. and Izinyon O. C. \\ Department of Civil Engineering, University of Benin, Benin City, Nigeria \\ Corresponding Author: *osagieosarenren@yahoo.com
}

https://doi.org/10.36263/nijest.2021.02.0320

\begin{abstract}
High voltage overhead transmission line route selection has become a vital component of the power transmission line project life cycle as demand for electricity has increased and global awareness of the environmental implications of large-scale power projects has grown. The project necessitates meticulous planning, engineering designs, facility installations, commissioning, and maintenance, as any errors made at this stage may have a flowing detrimental impact on the following phase, which may be too costly to fix. Using geographic information system (GIS), multicriteria decision analysis approach, and environmental impact factors strategies, this study determines the best route from existing geographical space between Lafia 330/132/33kV Substation in Nasarawa State and New Apo (Pigba) 330/132/33/kV Substation in the Federal Capital Territory, Central Nigeria, Abuja. Land use, land cover, and other environmental data were obtained by performing image classification on Landsat 8 satellite image using ArcGIS 10.1 to achieve this goal. Three key terrain elements were identified to define the land cover types: built-up areas, vegetation, and water bodies. These layers were created to reveal the locations of significant settlements, geological formations, and the HV-OHTL route that avoided crossing protected areas. Using pair-wise comparison of analytic hierarchy process (AHP) approach, each criterion evaluated was assigned relative weight that shows their level of influence on the proposed power transmission line, and these were provided as GIS layers for visualizations. To build the cost surfaces assessed during route selection for HV-OHTL, weights derived from AHP method for each decision makers were applied to all layers to create the cost surfaces analyzed during route selection for $\mathrm{HV}$-OHTL.
\end{abstract}

Keywords: Geographic Information System (GIS), Multi-Criteria Decision Analysis (MCDA), Analytic Hierarchy Process (AHP), Least Cost Path, High Voltage Overhead Transmission Line (HV-OHTL), Substation

\subsection{Introduction}

The high-voltage over-head transmission line (HV-OHTL) is a dependable option for bulk power transmission around the world. Route selection is a difficult engineering decision making. For example, a balance is struck in the United Kingdom (UK) between constitutional demands, engineering needs, economic viability, land use land cover (LULC), and environmental stressors (Marshall and Baxter, 2002). This is analogous to what is required to achieve a route that is technically, financially, and commercially viable while also avoiding or minimizing environmental impact. The underlying issues in HV-OHTL route selection projects have always attracted public interest and sparked heated debates, with the fundamental issues frequently focusing on local effects such as visual configurations of associated facilities and their environmental impacts rather than the project's overall benefits to society. Given the scope of public and regulatory investigations, the environmental impact statement resulting from such plans must be impartial and transparent in the route selection process. The method is founded on evidence that the non-aesthetic layouts, the grade of visual breaks, and how environmental consequences can be minimized by well-planned route selection are significant issues of HV-OHTL. 
The goal of HV-OHTL optimum routing is to efficiently transfer large amounts of electricity from the send end to the receiving end, where electricity is consumed at a break-even cost. For example, in the United Kingdom, this is frequently done at voltage levels of $132 \mathrm{kV}, 275 \mathrm{kV}$, or $400 \mathrm{kV}$ (Scottish power, 2001), whereas in Nigeria, power transmission voltage levels are $330 \mathrm{kV}$ and $132 \mathrm{kV}$. The influence on the right-of-way increases as the transmission voltage level rises. Transmission towers and lines are very hard to conceal, but there is a lot that can be done to make them less conspicuous and attractive. In both rural and urban areas, this includes suitable corridor site selection, landscaping, and screening. However, transmission line location constraints are typically greater in urban areas. Existing development and a lack of right-of-way may limit the best locations for HV-OHTL project. In rural locations, there is sufficient corridor for HV-OHTL to be built. The area enables right-of-way determination, project route alignment and development.

The HV-OHTL is a large linear structure erected in a landscape setting, making it the most important in determining environmental variables that influence the best power transmission line routing. All those parameters that influence route decisions at varied degrees and phases of project installation and operations are all those parameters that exist in a transmission line right-of-way. These variables can have a direct or indirect impact on the path, and they might be apparent or invisible. Landscape environmental variables were primarily used as criteria in this study to aid in the HV-OHTL selection. Integrating MCDA techniques into GIS-based processes during HV-OHTL selection planning is helpful because it allows value judgments to be introduced into GIS-based decision-making procedures and feedback on their consequences for policy implementation and evaluation (Malczewski and Rinner, 2015). Although this combination looks to be the finest option, it is just one of many options available in practice (Schito et al., 2021). Electricity demand is rising internationally as a result of rapid population increase (International Energy Agency, 2019), and the benefits of a reliable and high-quality electricity supply to customers boost economic growth and social-economic development (Taylor, 2017).

\subsection{Methodology}

\subsection{Description of study area}

The study area is located between the Federal Capital Territory (FCT) and Nasarawa State. The planned proposal for constructing a 330kV high voltage transmission line from Lafia's 330/132/33kV substation to Abuja's New AP0 (Pigba) 330/132/33kV substation is covered within the study area. It lies between Latitude $08^{\circ} 20^{\prime} 01^{\prime \prime} \mathrm{N}$ to $09^{\circ} 04^{\prime} 00^{\prime \prime} \mathrm{N}$ and Longitude $07^{\circ} 16^{\prime} 55^{\prime \prime} \mathrm{E}$ to $08^{\circ} 50^{\prime} 32^{\prime \prime} \mathrm{E}$ (Figure 1).

\subsection{Geographic Information System Software, In-Built Tools and Applications}

An advanced version of the Environmental Systems Research Institute's (ESRI) product, ArcGIS Desktop 10.1, was used in this investigation. It was possible to create, query, mapped, and analyse cell-based raster data, perform integrated raster/vector analysis, derive new information from existing data, query across multiple data layers, and fully integrate cell-based raster data with traditional vector data sources using ArcGIS Spatial Analyst. In addition, ArcGIS Spatial Analyst was integrated into the ArcGIS interface, allowing users to access all of the available functionalities to obtain information about geospatial data such as terrain analysis, spatial relationships, suitable locations, and the total cost of travel from one point to another (ESRI White Paper, 2001).

Additionally, MS Excel 2014 and MS Word 2014 were employed for a variety of tasks, including graph production, report writing, and AHP computations. 


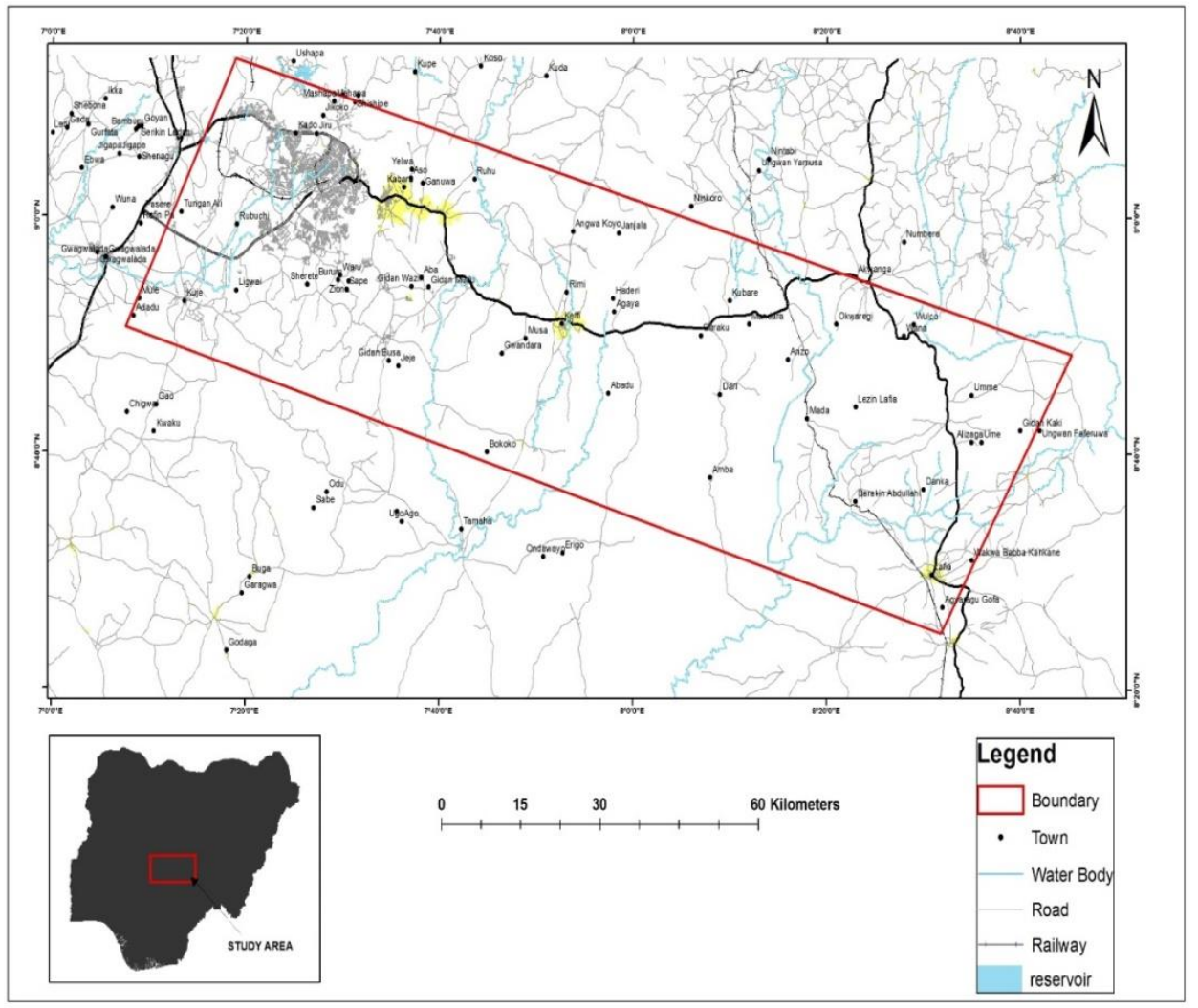

Figure 1: Research study area

\subsection{Data sources and collections}

DEM, Slope, Soil, Erosion, Geology, Satellite Imagery, Land Use Land Cover, and Road Network layers are among the data needed for this project.

They are made up of a variety of ages, sources, formats, qualities, and scales that have been collected from various organizations. The datasets and their sources and ages are presented in Table 1.

Table 1: Datasets properties and sources

\begin{tabular}{|c|c|c|c|c|c|}
\hline $\mathrm{S} / \mathrm{N}$ & Data Names & Scale /Year & Data Sources & Year & Format \\
\hline 1 & $\begin{array}{l}\text { Digital Elevation Model } \\
\text { (DEM) }\end{array}$ & 30m Resolution & $\begin{array}{l}\text { 30m DEM downloaded from } \\
\text { United states geological survey } \\
\text { (USGS) (www.explore.USGS.gov) }\end{array}$ & 2014 & Raster \\
\hline 2 & Slope & 30m Resolution & 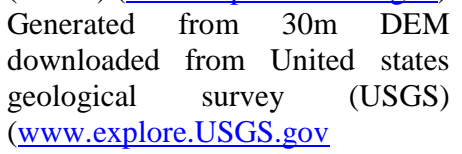 & 2014 & Raster \\
\hline 3 & Soil & $1 \mathrm{~km}$ Resolution & $\begin{array}{l}\text { Harmonised World Soil Database } \\
\text { (HWSD) www.fao.org }\end{array}$ & 2013 & Raster \\
\hline 4 & Erosion & $1 \mathrm{~km}$ Resolution & $\begin{array}{l}\mathrm{K} \text { factor of Soil data (generated } \\
\text { from soil data) }\end{array}$ & 2013 & Raster \\
\hline 5 & Geology & $1: 50,000$ & Nigerian Geological Survey & 2005 & Raster \\
\hline 6 & Satellite Imagery & 30m Resolution & $\begin{array}{l}\text { Landsat } 8 \text { satellite Image } \\
\text { (www.explore.USGS.gov) }\end{array}$ & 2018 & Raster \\
\hline 7 & Land Use Land cover & 30m Resolution & $\begin{array}{l}\text { Generated from Landsat } 8 \text { satellite } \\
\text { Image }\end{array}$ & 2018 & Raster \\
\hline 8 & Road network & & $\begin{array}{l}\text { Vector data from Open street map } \\
\text { (www.bbbike.com ) }\end{array}$ & 2018 & Vector \\
\hline
\end{tabular}

\subsubsection{Digital Elevation Models (DEM)}

Digital elevation models are raster-based data (e.g., a grid of squares or a Triangular Irregular Network, TIN) that provide a digital representation of data across a defined region at a specific scale, in this example 30 meters. The elevation of the route (site) varies from $65 \mathrm{~m}$ to $1200 \mathrm{~m}$ (Figure 2). 


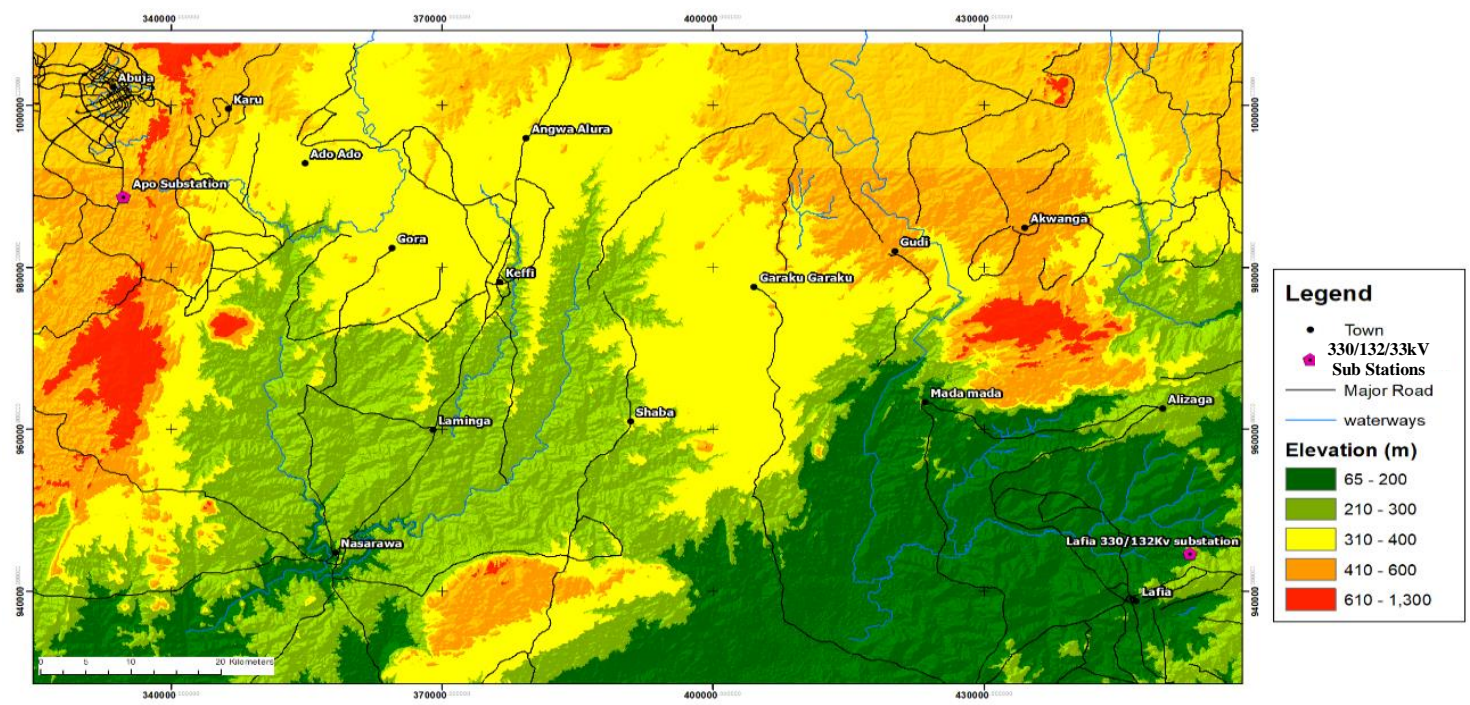

Figure 2: DEM of study area

\subsubsection{Slope (Using 30m DEM)}

Using the spatial toolbox in ArcGIS, the slope data was created from the 30m DEM (Figure 3). The Slope data specifies the greatest rate of change in value from one cell to the next, or a measure of change in surface value over distance, either in degrees or as a percentage. The flatter the terrain, the lower the slope value; the steeper the terrain, the greater the slope value. These two characters are crucial when it comes to tower design and installation. The slope classes listed in Table 2 are commonly recognized in engineering practice, according to (ESU, 2010).

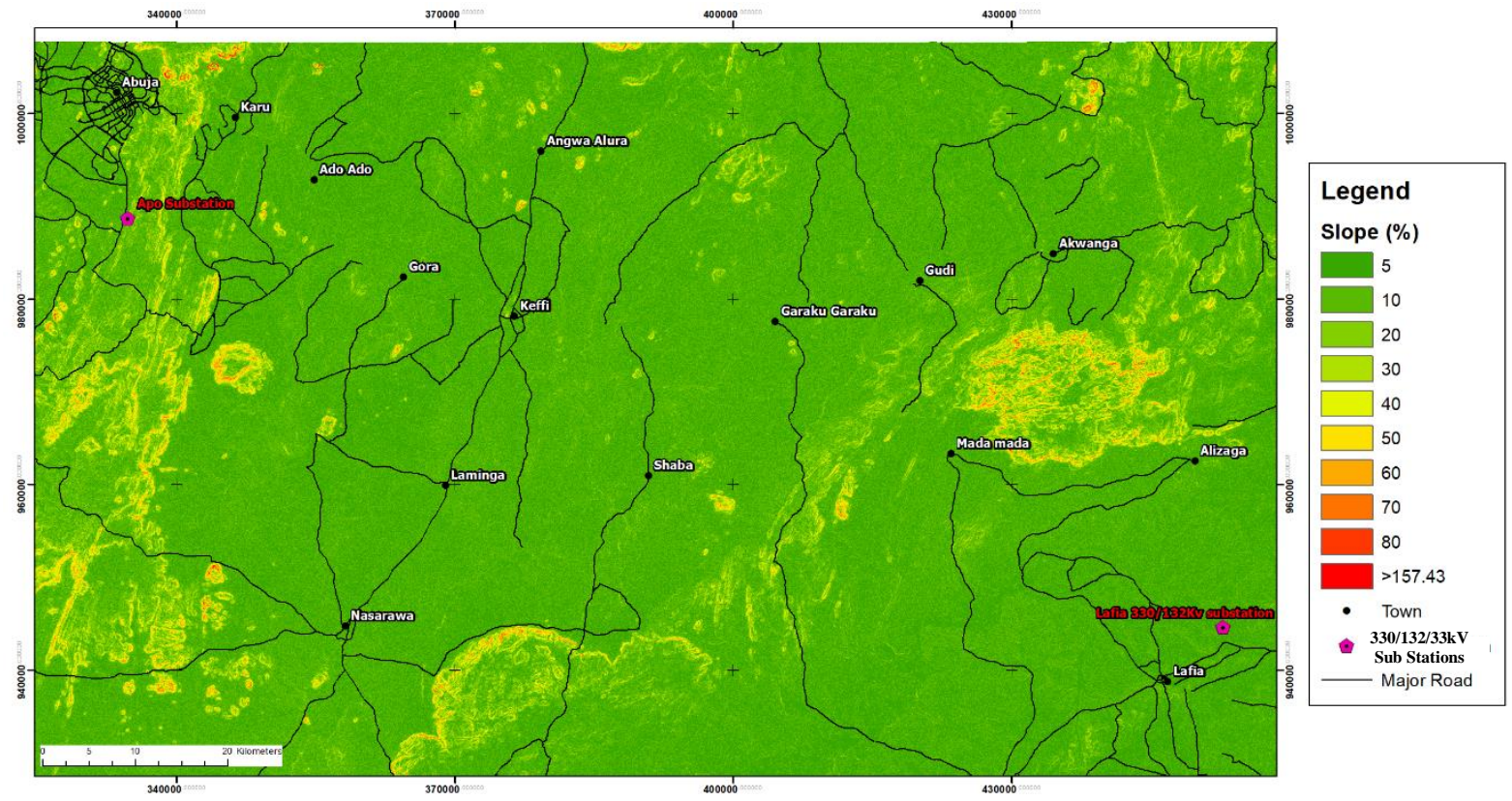

Figure 3: Slope classification in percentage

Table 2: Interpretation of slope classes (ESU, 2010)

\begin{tabular}{ll}
\hline Slope Description & Slope class (\%) \\
\hline Nearly Level & $0-2$ \\
Gently Sloping & $2-5$ \\
Moderately Sloping & $5-9$ \\
Strongly Sloping & $9-15$ \\
Moderately Steep & $15-30$ \\
Steep & $30-50$ \\
Very Steep & $>50$ \\
\hline
\end{tabular}




\subsubsection{Soil layer}

Various soil classes were considered based on textual soil properties as it relates to the strength of soil present at the project site. Data for this purpose were acquired from the Harmonized World Soil Geodatabase (HWSD version 1.2), the HWSD is composed of a raster image file and a linked attribute database. The raster database consists of 21,600 rows and 43,200 columns, of which 221 million grid cells cover the globe's land territory (FAO, 2009). Organic carbon, $\mathrm{pH}$ value, water storage capacity, soil depth, cat-ion exchange capacity of the soil and the clay fraction, total exchangeable nutrients, lime and gypsum contents, sodium exchange percentage, salinity, textural class, and granulometry are all linked to each grid cell in the database. HWSD uses GIS software to display or query soil compositions in terms of user-selected soil parameters; in this case, the database was loaded into Arc map 10.1. The soil layer is shown in Figure 4 and it gives the major classes of soil within the region considering their textural properties. About $60 \%$ of the soil types were seen to be clay loam, and the remaining $40 \%$ consist mainly of sand and loamy soils.

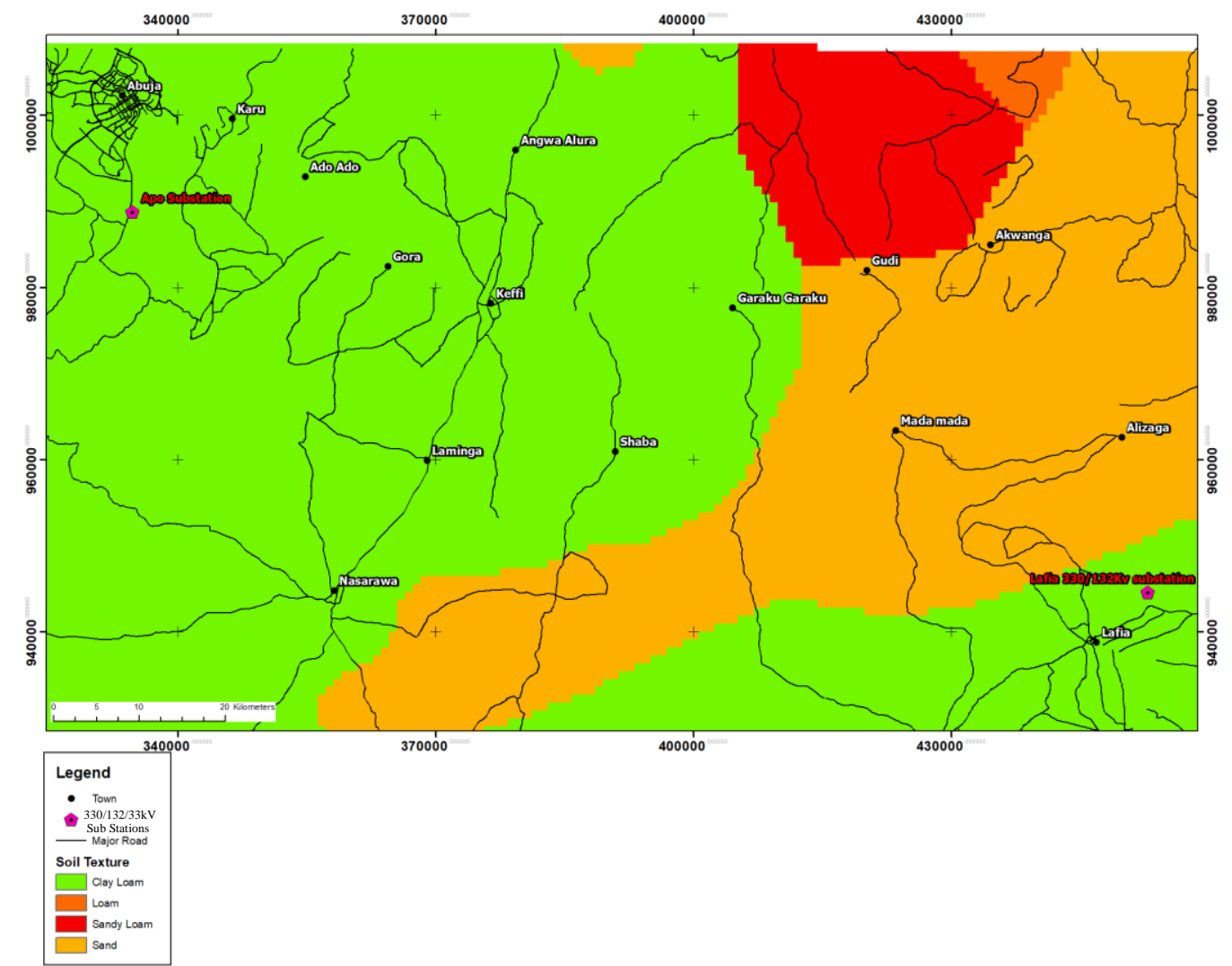

Figure 4: Soil textural classification

\subsubsection{Geology}

Figure 5 shows the geological layer created using a Nigerian geological map. It was digitized using ArcGIS 10.1 software and geo-referenced for the study area. The site's geological formation reveals information about the material strength that should be considered during tower foundation design and construction. 

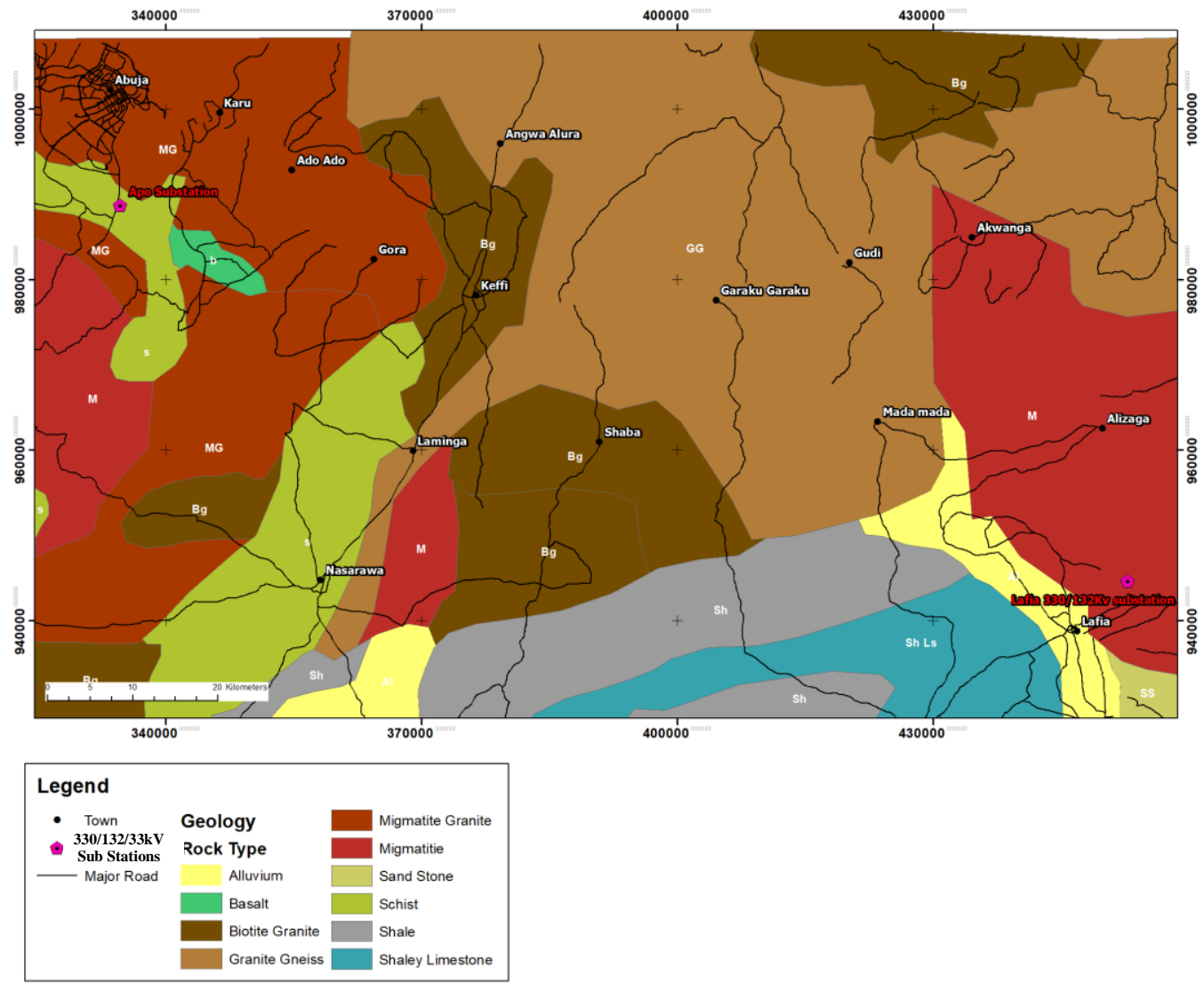

Figure 5: Geological map

\subsubsection{Land Use and Land Cover}

The land cover map was created using ArcGIS 10.1 and a supervised image classification on a Landsat-8 satellite image using the USGS Land Use Land Cover categorization scheme (Chandra et al., 2014). Built-up, Vegetation, and Water Bodies were the three key land class features used to determine the Land Cover type. A false color composite was created using a Landsat Band combination of five near-infrared (5NIR), 4(Red), and 3(Green), as seen in Figure 6. Using colour discrimination, vegetation appears red, built-up areas seem yellow, and water bodies appear blue. A training data set was constructed by picking multiple known locations to represent each class of information, as shown in Figure 6, and then utilized to perform image classification.

These layers display the locations of significant towns and water bodies, as well as power line route selection, which minimizes tower spotting in water bodies and avoids routing power lines through villages as much as possible. 


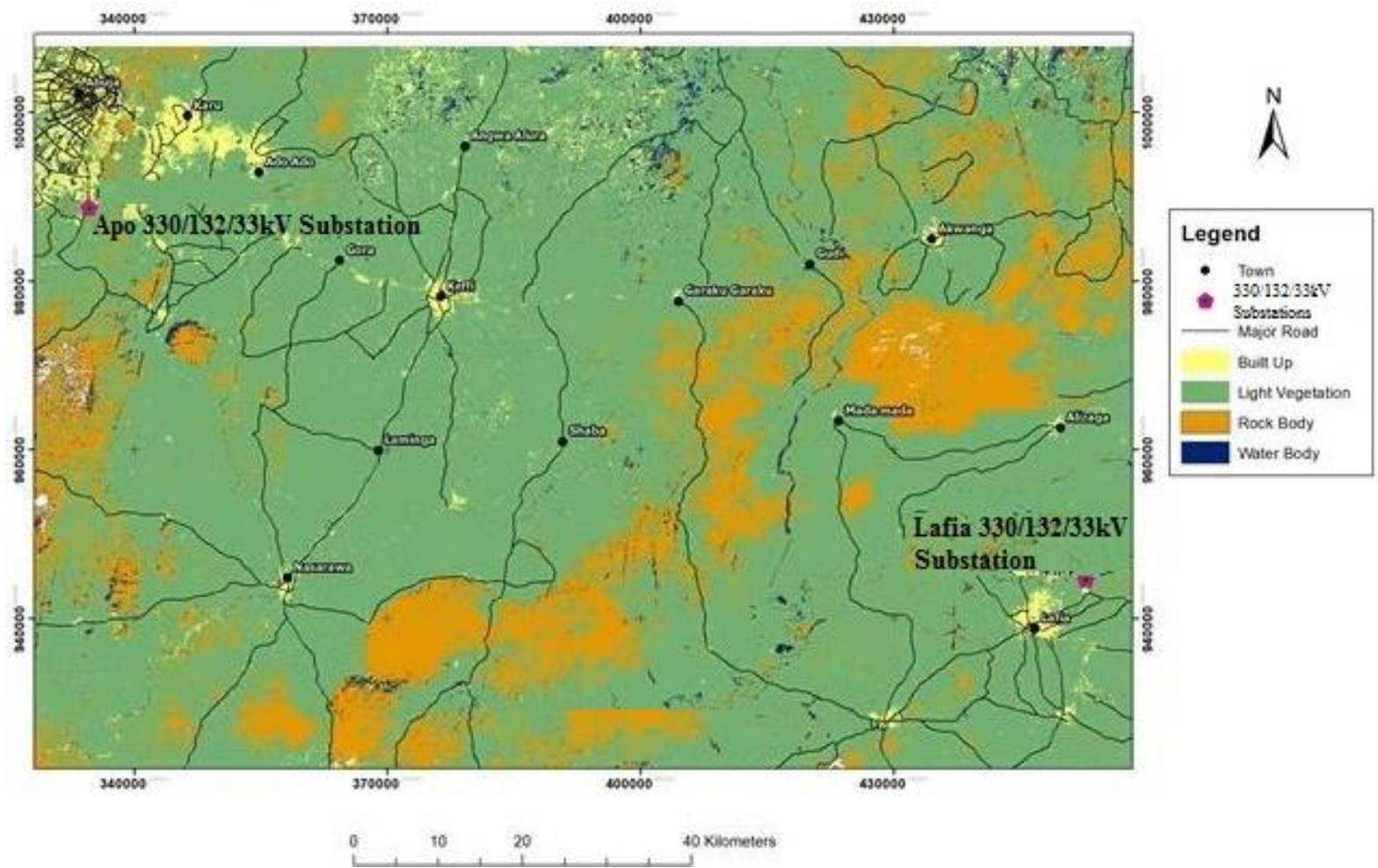

Figure 6: Land cover map showing land cover classes

\subsubsection{Erosion}

For the estimation of soil erosion in the study area, parameters from the soil layer of the harmonized world soil geo-database (HWSD) were used, and the distribution of soil particles was taken into account. Although soil erosion factor $K$ is influenced by particle size distribution, organic matter content, soil structure, and permeability, the silt percentage content from whole top soil content is the most important factor in soil erosion because silt is easily detached and tends to crust, resulting in high runoff rates. It has been proven that soils with a high silt concentration are the most prone to erosion. The erosion factor $K$, was calculated using (William, 1995) equation. To estimate the erosion factor $(K)$ Equation1 is used.

$K_{U S L E}=f_{\text {csand }} \times f_{\text {ci-si }} \times f_{\text {orgc }} \times f_{\text {hisand }}$

Where each factors are calculated using Equation $2-5$

$$
\begin{aligned}
& f_{\text {csand }}=\left(0.2+0.3 \exp \left[-0.256 . m_{s} \cdot\left(1-\frac{m_{\text {silt }}}{100}\right)\right]\right) \\
& f_{\text {ci-si }}=\left(\frac{m_{\text {slit }}}{m_{c}+m_{\text {slit }}}\right)^{0.3} \\
& f_{\text {orgc }}=\left(1-\frac{0.0256 . \text { orgC }}{\text { orgC }+\exp [3.72-2.95 . \text { orgC }]}\right) \\
& f_{\text {hisand }}=\left(1-\frac{m_{s}}{\left(1-\frac{m_{s}}{100}\right)+\exp \left[-5.51+22.9\left(1-\frac{m_{s}}{100}\right)\right]}\right)
\end{aligned}
$$

The computed values using Equations $2-5$ are shown in Table 3 .

Where:

$m_{s}$ : The percentage of sand fraction content (0.5-2 mm particle diameter)

$m_{\text {slit }}$ : The percentage of silt fraction content $(0.002-0.05 \mathrm{~mm}$ particle diameter)

$m_{c}$ : The percentage of clay fraction content $(<0.002 \mathrm{~mm}$ particle diameter)

$\operatorname{org} C$ : The percentage of organic carbon fraction content $(\%)$ 
Table 3: Calculation for each soil class

\begin{tabular}{lccccccccc}
\hline Soil Textural & & & & & & & & \\
Class & SAND & SILT & CLAY & Organic Content & fcSand & fcl_si & Forgc & Fhisand & k factor \\
\hline Sandy Loam & 81 & 9 & 10 & 0.55 & 0.20 & 0.80 & 1.00 & 0.74 & 0.12 \\
Loam & 42 & 36 & 22 & 1.00 & 0.20 & 0.87 & 0.99 & 1.00 & 0.17 \\
Sand & 43 & 34 & 23 & 1.40 & 0.20 & 0.86 & 0.98 & 1.00 & 0.17 \\
Sand & 73 & 18 & 9 & 1.40 & 0.20 & 0.89 & 0.98 & 0.92 & 0.16 \\
Sand & 73 & 18 & 9 & 1.40 & 0.20 & 0.89 & 0.98 & 0.92 & 0.16 \\
Clay Loam & 49 & 29 & 22 & 1.01 & 0.20 & 0.84 & 0.99 & 1.00 & 0.17 \\
Clay Loam & 49 & 29 & 22 & 1.01 & 0.20 & 0.84 & 0.99 & 1.00 & 0.17 \\
\hline
\end{tabular}

The generated erosion map is shown in Figure 7, with average values ranging between $0.11-0.17$. When erosion ratio is less than 10 , it indicates non-erodible soil, where erosion ratio ranges from 12 to 115 shows erodible soil.

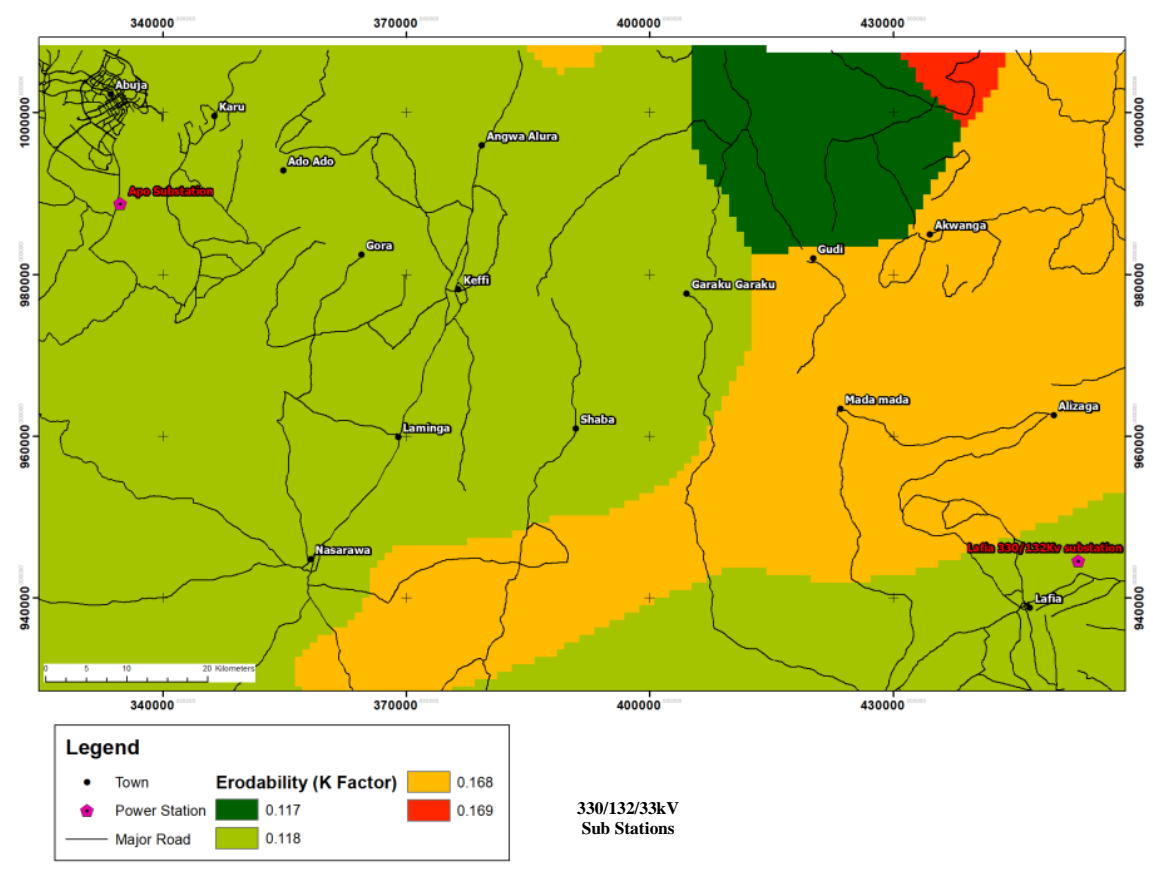

Figure 7: Soil erosion map

\subsubsection{Road network layer}

The road network refers to the roads that exist in the research area. The proximity of the HV-OHTL route to the main road is critical because it minimizes the cost of transportation of men and materials during project construction, commissioning, and maintenance period. The road layer (Figure 8) was retrieved as a vector data type from the open street map database, and the networks were updated using archival satellite imagery from Google Earth Engine from 2019. The primary route in the study locations is depicted in Figure 8. 


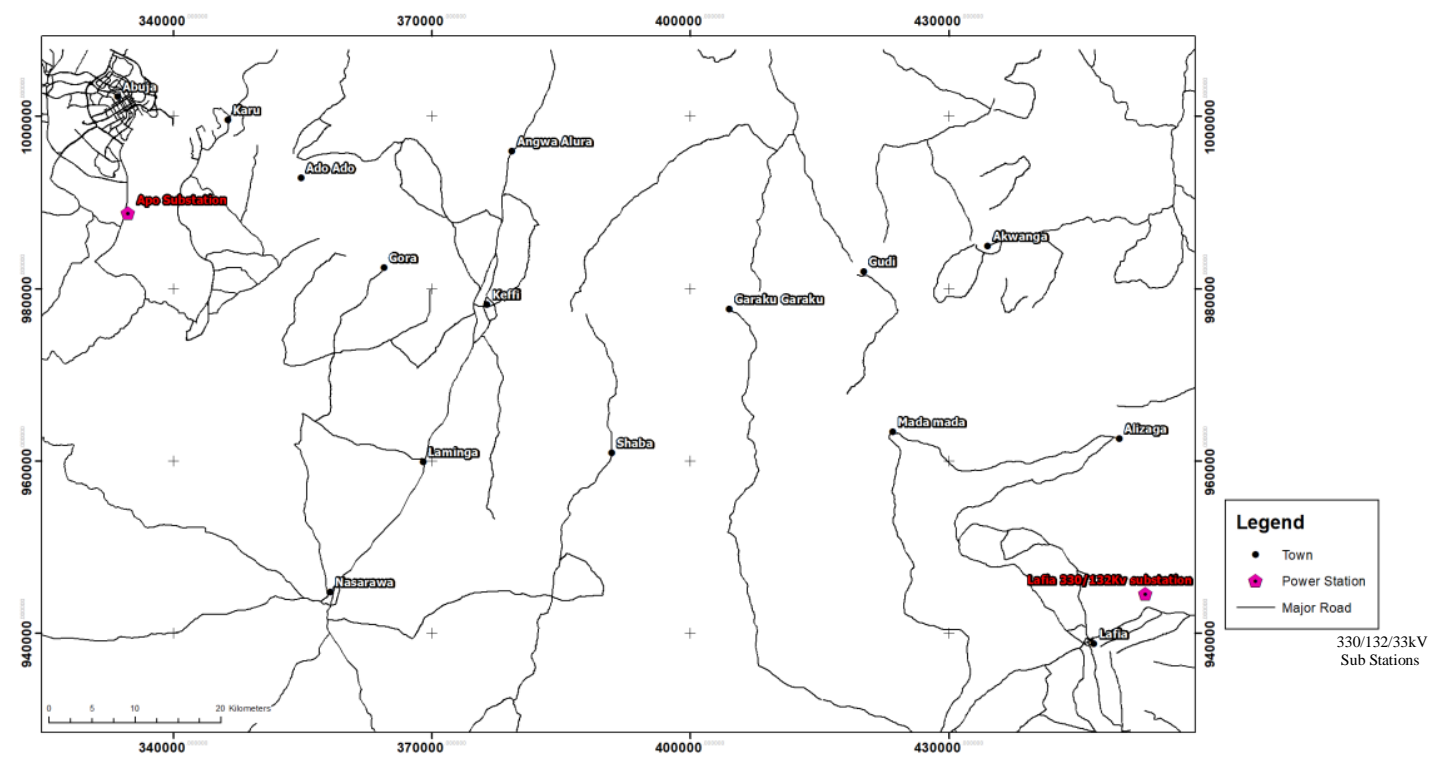

Figure 8: Major roads around study area

\subsection{Results and Discussion}

The aforementioned layers were classed as "a soil map displaying distinct soil types" and "other variables exhibiting different layers," respectively. In this instance, it's preferable to give the soil units a suitability property for evaluating different types of tower foundations. Because different soil types may have varied suitability's, a classification may mix soil units of diverse types into the same category of soil suitability- based on how appropriate the current characteristics along the proposed HV-OHTL project route are. For raster calculations, the data was first transformed to usable raster sets. Consequently, the most suitable features for route selection were ranked as 1 and the worst features ranked as 9 in-line with Saaty scale (1980). When this method of overlaying the raster layers was used, the cell that has the minimum value corresponds to the most suitable cell for HV-OHTL project routing. Table 4 shows the assigned values to each layer.

The reclassification values for each raster layer were redistributed using the tool in Arc map for reclassification purposes, taking into account Table 4.

The relative weights determinations of the route criterion, random index, Eigen values, and consistency of the three decision makers are shown in Table 5-7; while the summary of the weight selection by each decision maker is shown in Table 8 . 
Table 4: Reclassification of dataset

\begin{tabular}{lc}
\hline Layer/ Class & Reclassified Value \\
\hline Land Cover & 2 \\
Vegetation/farmland, Rock body & 9 \\
Built up, Water body & \\
Soil & 1 \\
Clay Loam & 2 \\
Loam, Sandy Loam, Sand & \\
Erosion & 1 \\
$0.12-0.17$ & \\
Slope (\%) & 1 \\
$0-10$ & 3 \\
$10-20$ & 4 \\
$20-30$ & 6 \\
$30.1-40$ & 7 \\
$40.1-50$ & 8 \\
$50.1-60$ & 9 \\
$>60.1$ & \\
Road (m) & 1 \\
$0-500$ & 2 \\
$500-1000$ & 6 \\
$>1000$ & \\
Geology & 1 \\
Migmatitie, Granite, Gneiss, Biotite Granite, Migmatite Granite, Basalt & 2 \\
Alluvium, Schist & 3 \\
Sand Stone & \\
Shaley Limestone, Shale. & \\
\hline
\end{tabular}

Table 5: Decision matrix weights and consistency of decision maker I

\begin{tabular}{|c|c|c|c|c|c|c|c|c|c|c|c|}
\hline & & $\frac{0}{\text { ล }}$ & 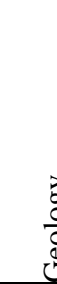 & & $\begin{array}{l}\overline{8} \\
\text { : }\end{array}$ & & 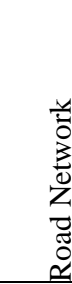 & 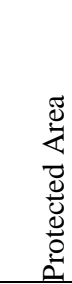 & $\begin{array}{l}\text { Weights } \\
(\%)\end{array}$ & \multirow{9}{*}{$\begin{array}{l}\lambda \max \\
\text { CI } \\
\text { RI } \\
\text { CR }\end{array}$} & \multirow{9}{*}{$\begin{array}{l}7.56 \\
0.093 \\
1.32 \\
7.10\end{array}$} \\
\hline & & 1 & 2 & 3 & 4 & 5 & 6 & 7 & & & \\
\hline Slope & 1 & 1 & 3 & 2 & 5 & 3 & 1 & 1 & 25.49 & & \\
\hline Geology & 2 & $1 / 3$ & 1 & 2 & 1 & 1 & $1 / 2$ & $1 / 2$ & 9.22 & & \\
\hline Erosion & 3 & $1 / 2$ & $1 / 2$ & 1 & $1 / 3$ & $1 / 4$ & $1 / 3$ & $1 / 4$ & 5.36 & & \\
\hline Soil & 4 & $1 / 5$ & 1 & 3 & 1 & 2 & $1 / 2$ & 1 & 11.87 & & \\
\hline Land Use Land Cover & 5 & $1 / 3$ & 1 & 4 & $1 / 2$ & 1 & $1 / 2$ & 1 & 10.81 & & \\
\hline Road Network & 6 & 1 & 2 & 3 & 2 & 2 & 1 & 3 & 22.69 & & \\
\hline Protected Area & 7 & 1 & 2 & 4 & 1 & 1 & $1 / 3$ & 1 & 14.56 & & \\
\hline
\end{tabular}

Table 6: Decision matrix weights and consistency of decision maker II

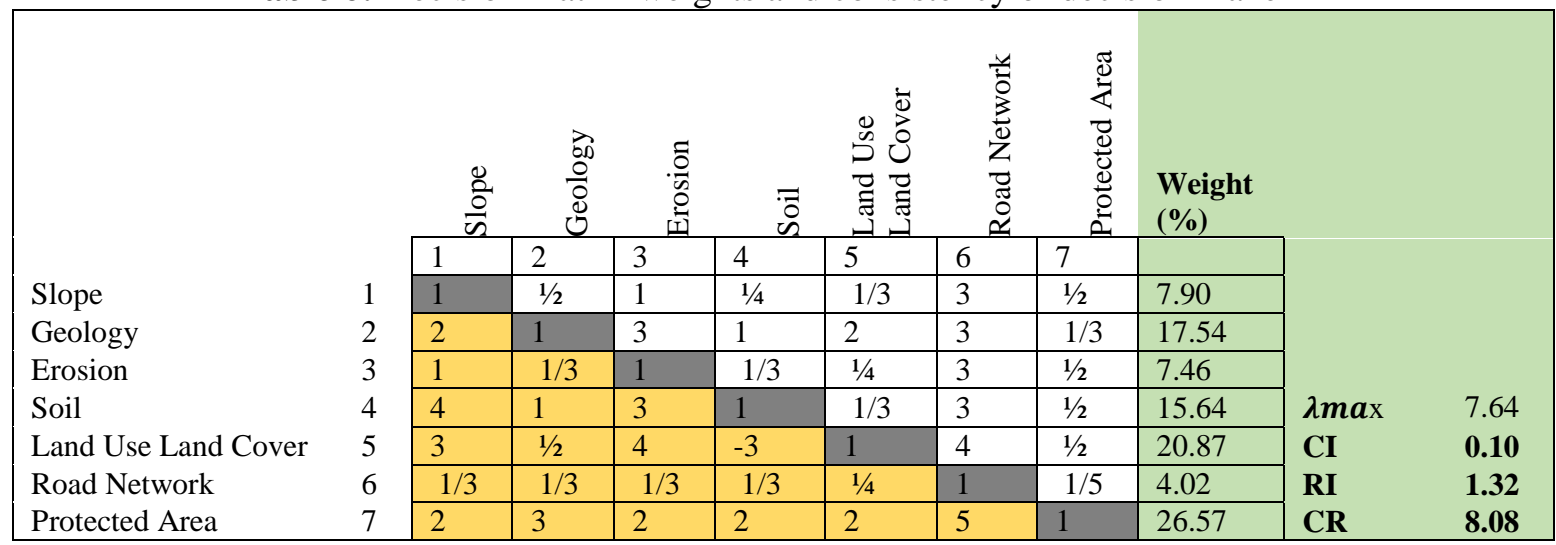


Table 7: Decision matrix weights and consistency of decision maker III

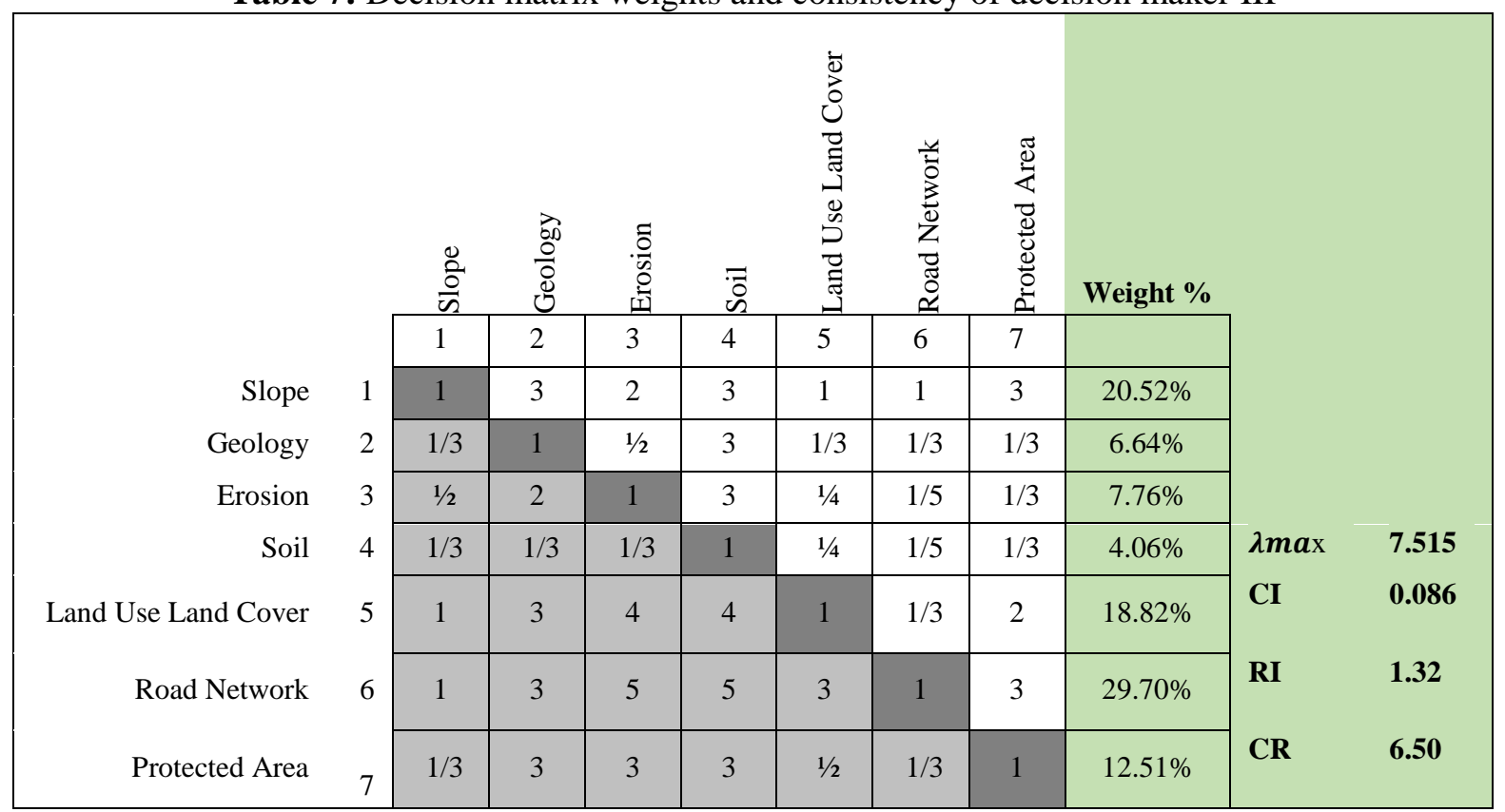

Table 8: Summary of weight selection by each decision maker

\begin{tabular}{|l|l|l|l|}
\hline \multirow{2}{*}{ Parameter } & \multicolumn{3}{|l|}{ Weight Selection (\%) } \\
\cline { 2 - 4 } & Decision maker I & Decision maker II & Decision maker III \\
\hline Slope & 25.49 & 7.90 & $20.52 \%$ \\
\hline Geology & 9.22 & 17.54 & $6.64 \%$ \\
\hline Erosion & 5.36 & 7.46 & $7.76 \%$ \\
\hline Soil & 11.87 & 15.64 & $4.06 \%$ \\
\hline Land Use Land Cover & 10.81 & 20.87 & $18.82 \%$ \\
\hline Road Network & 22.69 & 4.02 & $29.70 \%$ \\
\hline Protected Area & 14.56 & 26.57 & $12.51 \%$ \\
\hline
\end{tabular}

Table 9's Decision Maker I is a Principal Manager (Civil-Lines) who completed the decision matrix effectively, and when computed, the criteria slope of 25.49 percent is the highest relative weight and had the most influence on the HV-OHTL route selection. Decision Maker II, an environmental engineer, was tasked with identifying environmental impact assessment and recommending mitigation actions for the HV-OHTL project, and when the protected area of 26.57 percent was estimated, the decision matrix had a higher impact. The key worry of Decision Maker III, a maintenance engineer, was the availability of a good road network, which will provide access during the maintenance period with a 29.70 percent score.

\subsection{The cost distance and backlink raster layer}

A raster is initially created via a cost-distance analysis (Figure 9) that assesses the expense of travelling over a surface. The raster might utilize a single cost component, such as slope, or it could incorporate different sorts of charges. A cost direction raster, which advises a traveller which way incurs the least cost, and a cost accumulation raster, which keeps track of the overall effort expended as the traveller progresses, were developed using the cost raster. The least cost path between two points was calculated using these raster's, showing the simplest route rather than the shortest. The cost distance and back link raster were used to do the least-cost path analysis. The source cells and the weighted sum are used to create the cost distance raster. The cost distance operation works in the background in a similar way to the Euclidean distance operation, except it calculates the shortest weighted distance between the cells. The back link raster specifies the pixel that should be used to return to the destination cell (ArcGIS Help 10.1). 

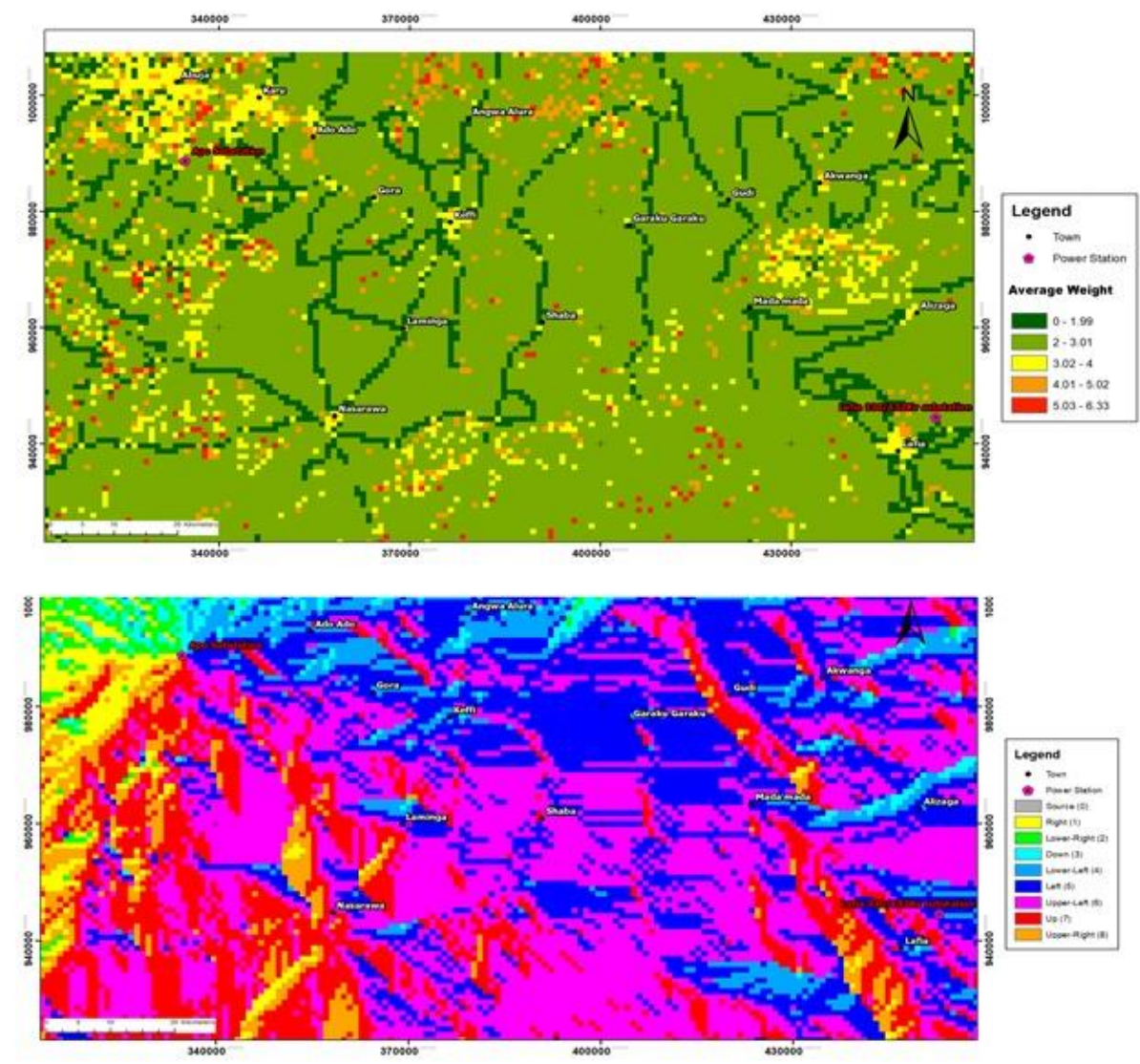

Figure 9: The cost distance and backlink raster layer

The route selected by Decision Maker I - III is represented in Figure 10, also the mean of the three decision makers was used to generate a fourth route. The total route lengths generated are shown in Table 8.

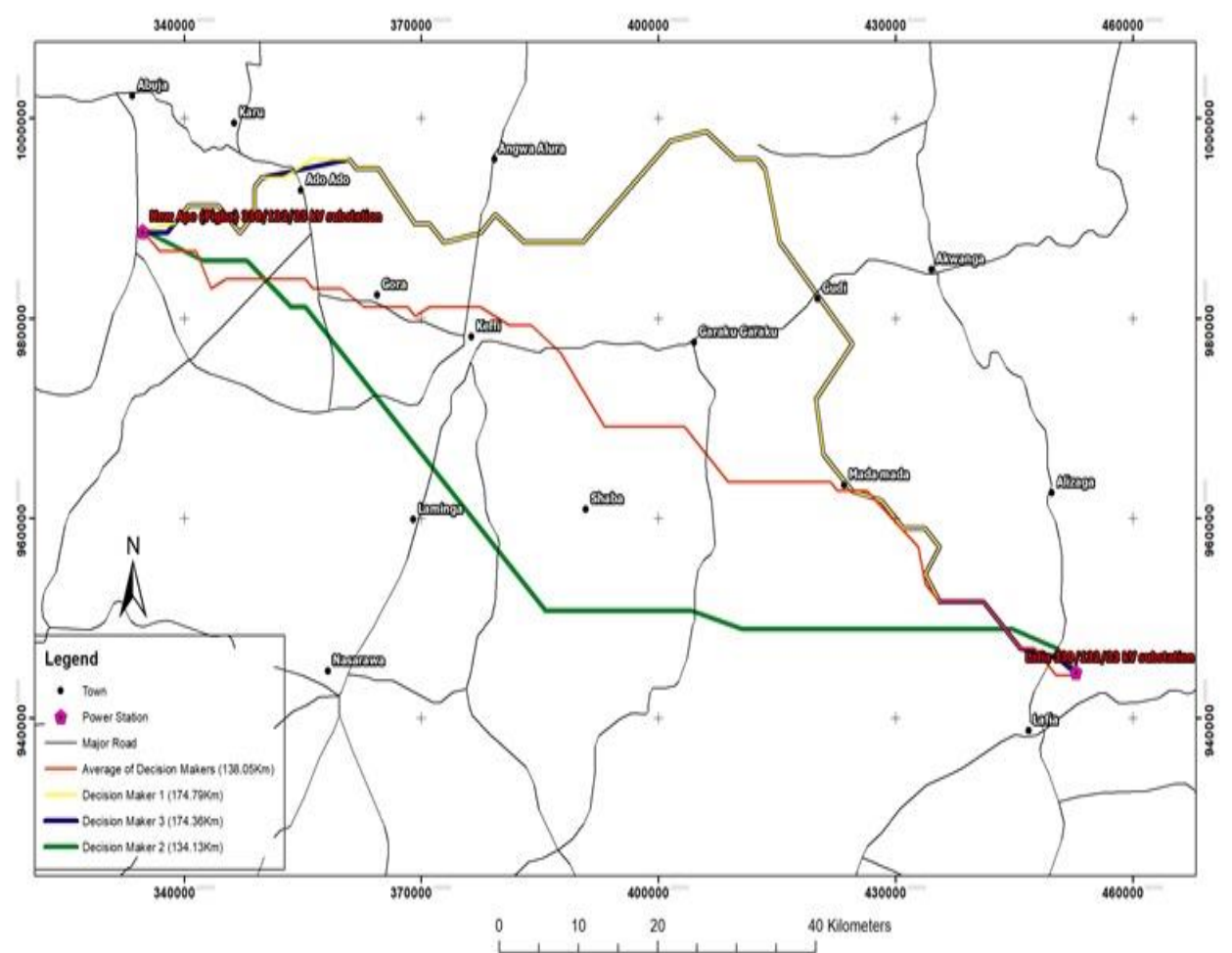

Figure 10: Route map showing preferred route of Decision Maker I-III and the mean route 
Table 9: Length of routes based on Decision Makers

\begin{tabular}{lccccc}
\hline Decision Makers & Route & $\begin{array}{c}\text { Route Length } \\
(\mathrm{km})\end{array}$ & Major Detours & $\begin{array}{c}\text { Max } \\
\text { Slope }(\%)\end{array}$ & $\begin{array}{c}\text { Average Slope } \\
(\%)\end{array}$ \\
\hline Decision Maker I & Route 1 & 174.79 & 30 & 11.1 & 0.9 \\
Decision Maker II & Route 2 & 134.13 & 9 & 24.1 & 1.5 \\
Decision Maker III & Route 3 & 174.36 & 32 & 10.3 & 1.1 \\
Mean of Decision Makers & Route 4 & 138.05 & 20 & 10.0 & 1.1 \\
\hline
\end{tabular}

The number of angle points on each route, as well as the total distances, were taken into account while choosing the optimum route. The maximum and average slopes as they affect engineering design for each route were also taken into account.

\subsection{Conclusions}

Slope, Geology, Erosion, Soil, Land Use Land Cover, Road Network, and Protected Zone layers are part of the data set used in this investigation. To develop reclassified layers, these layers are put through a process. The applications for reclassification are carried out based on the viability of the layers' features. According to the HV-OHTL expert's understanding, the features are ranked by values ranging from 1 to 9 .

On HV-OHTL, there are three decision makers with various professional backgrounds. The AHP approach allows for the decision makers' preferences to be reflected. Because the route selection process for HV-OHTL is viewed from a distinct perspective, each decision maker prioritizes various layers. The cost surfaces are developed based on the preferences of each decision maker in order to describe the least expensive paths. The length, cost, impact aspects, and risk of the route possibilities are all considered. The cost of each route is calculated using a strong power line design program, power line system computer assisted and drafting, or PLS- CADD, that is generated from an actual HV-OHTL design. Material, installation, and shipping costs, as well as the cost of the cell where the power structure is located, are all included in the cost criterion. The number of intersections with linear structures is used to calculate the risk factor. The effect factor is calculated using the overall area $\left(6707 \mathrm{~km}^{2}\right)$ of the route right -of- way, which passes through settlements, agricultural areas, and forests. The decision makers' consensus is used to calculate the weight of each criterion using the AHP pairwise comparison approach. The decision makers define the convenient preference functions and thresholds for each criterion in terms of its attributes.

\section{Recommendations:}

Prior to construction, the Power Transmission Company must be aware of all legal requirements for a new HV-OHTL. State laws and regulations must be observed and implemented to the letter. All stakeholders must be identified and their concerns addressed throughout the planning stage of a project. This will save time and money by avoiding unnecessary project delays.

Because the resolution and precision of the data have a direct impact on the output information's reliability, the DEM layer should be generated using LiDAR data with a high resolution and operational flexibility. Small elevation changes will make the DEM more responsive. It is recommended that the numbers and background of decision makers be increased with a view to achieving unbiased and reliable solution for HV-OHTL routing decision problems.

The model developed in this work should also be applicable to other voltage levels of power transmission lines route selection challenges, as well as other linear engineering structures. A national information centre or data bank should be formed with the goal of storing, updating, converting, and evaluating data that cabe used for research and other purposes. Civil-lines design engineer, environmental engineer, and maintenance engineer of HV-OHTLs projects are among the professionals chosen for consultation. They solely represent the Transmission Company of Nigeria's SMEs (TCN). Additional interviews with specialists from the Federal Ministry of Power, as well as officials from the Federal Ministry of Environment and landscape preservation organizations, would provide a more thorough assessment of the final route. 


\section{References}

bbbike.com. (2019). bbbike.com-This website is for sale!-bbbike bb bike Resources and Information. Www.bbbike.com. Retrieved 2 January 2019, from https://www.bbbike.com

Chandra, A.M. and Gosh, S.K. (2014): Remote Sensing and Geographic Information System, publish by N.K. Mehra for Narosa Publishing House PVT. LTD, $14^{\text {th }}$ Edition, New Delhi, India.

ESRI White Paper, 2001 ArcGIS ${ }^{\text {TM }}$ Spatial Analyst: Advanced GIS Spatial Analysis Using Raster and Vector Data, USA

ESU, I.E. (2010). Soil Characterization, Classification and Survey, HEBN Publishers Plc. Ibadan, Nigeria. $1^{\text {st }}$ Edition.

FAO. (2019). Food and Agriculture Organization of the United Nations. Food and Agriculture Organization of the United Nations. Retrieved 2 January 2019, from https://www.fao.org

International Energy Agency, (2019), key World Energy Statistics 2019, Paris (France): OECD Publishing. URLhttps://www.oecd-1library.org/content/publication/7ib3ce84-en.

multi-criteria site analysis. URISA-WASHINGTON DC-, 12(3), 5-18.

Malczewski, J. and Rinner, C. (2015). Multi-criteria decision analysis in geographic information science (p. 331). New York: Springer. https://doi.org/10.1007/978-3-540-74757-4

Marshall, R. and Baxter, R. (2002). Strategic Routing and Environmental impact assessment for overhead electrical transmission lines, policy and practice. Journal of Environmental planning and management

Saaty, T.L. (1980). The analytic hierarchy processes. New York. McGraw-Hill.

Scottish power (2001) Overhead Transmission Lines: Routing and Environmental Impact Assessment: The Scottish Power Approach (Glasgow, Scottish Power).

Schito, J., Moncecchi, D. and Raubal, M. (2021). Determining transmission line path alternatives using a valley-finding algorithm. Computers, Environment and Urban Systems, 86, 101571. https://doi.org/10.1016/j.compenvurbsys.2020.101571

Taylor, M. J. (2017). Energy for the world's kitchens: Biomass for survival in the past, present, and future. In Handbook on the Geographies of Energy. Edward Elgar Publishing. https://doi.org/10.4337/9781785365621.00010.

United States Geological Survey (USGS), (2018). EarthExplorer. Earthexplorer.usgs.gov. Retrieved 2 January 2018, from http://earthexplorer.usgs.gov/.

Williams, J.R. (1995) Chapter 25; The EPIC. In V.P. Singh (ed.) model Computer models of watershed hydrology. Water Resources Publications, pp. 909-1000. 